ANFUSINA: JOURNAL OF PSYCHOLOGY

http://ejournal.radenintan.ac.id/index.php/anfusina

DOI://dx.doi.org/10.24042/ajp.v2i1.4148

Volume 2, Nomor 1, April Tahun 2019

\title{
KECENDERUNGAN PERILAKU BULLYING DITINJAU DARI TIPE KEPRIBADIAN BIG FIVE
}

\author{
Ceria Pertiwi \\ UIN Raden Intan Lampung \\ ceriapertiwi92@gmail.com
}

\begin{abstract}
This study was conducted to determine the tendency of bullying behavior in terms of five personality types. The sample of this study was 86 students from Bandar Lampung High School 7. The sampling technique used was purposive sampling. The analysis used Multiple Regression Analysis at a significance level of 0.05. The results showed that two out of five big five personality types had a significant relationship with the tendency of bullying behavior, namely emotional stability and intellect. Type of emotional stability personality with regression cooficiency -0.888 ( $p=$ 0.007) has a negatively significant relationship with the tendency of bullying behavior. The type of intellect personality with regression cooficiency $1.159(p=0.003)$ has a significantly positive relationship with bullying behavior. the proportion of variance of the big five personality explained by the independent variable is $27.5 \%$, while the remaining $72.5 \%$ is influenced by other variables
\end{abstract}

\footnotetext{
Abstrak

Penelitian ini dilakukan untuk mengetahui kecenderungan perilaku bullying yang ditinjau dari lima tipe kepribadian. Sampel penelitian ini adalah siswa SMA Negeri 7 Bandar Lampung sebanyak 86 orang. Tekhnik sampling yang digunakan adalah purposive sampling. Analisis yang digunakan
} 


\begin{abstract}
Multiple Regression Analysis pada taraf signifikansi 0,05. Hasil penelitian menunjukkan dua dari lima tipe kepribadian big five memiliki hubungan yang signifikan degan kecenderungan perilaku bullying yaitu emotional stability dan intellect. Tipe kepribadian emotional stability dengan koofisien regresi $-0,882(\mathrm{p}=0,007)$ memiliki hubungan yang signifikan secara negatif dengan kecendrungan perilaku bullying. Tipe keribadian intellect dengan koofisien regresi 1,159 ( $\mathrm{p}=0,003)$ memiliki hubungan yang signifikan secara positif dengan perilaku bullying. proporsi varians dari kepribadian big five yang dijelaskan oleh variabel independen adalah sebesar $27,5 \%$, sedangkan $72,5 \%$ sisanya dipengatuhi oleh variabel lain
\end{abstract}

Keyword: big five personality, bullying, family, rural, urban

\title{
Pendahuluan
}

Remaja (adolescence) adalah individu yang sedang berada pada masa perkembangan transisi antara masa anak-anak dan masa dewasa. Fokus remaja pada perkembangan sosialnya ditandai dengan mulai memisahkan diri dari orang tua menuju kearah teman sebaya. Santrock (2003) mengungkapakn bahwa bagi remaja, hubungan teman sebaya merupakan bagian yang paling besar dalam kehidupannya. Fokus dari hubungan teman sebaya untuk disukai oleh teman sekelasnya namun hal ini tidak terlepas dari yang namanya penolakan dikarenakan beberapa sebab, sehingganya memberi pengaruh buruk pada perkembangan psikologisya.

Istilah bullying sudah tidak asing lagi di kalangan remaja terkhususnya di sekolah tempat mereka belajar. Bullying adalah sebuah situasi di mana terjadinya penyalahgunaan kekuatan atau kekuasaan yang dilakukan oleh seseorang atau sekelompok (Sejiwa, 2008). Istilah bullying juga di kenal dengan sebutan "penindasan" yakni tindakan intimidasi yang dilakukan pihak yang lebih kuat terhadap pihak yang lebih lemah (Coloroso, 2007). Dalam hal ini, perilaku bullying sangatlah berdampak negatif bagi semua pihak terkhusus kepada korban dan pelaku bullying itu sendiri.

Melakukan bullying terhadap orang lain sebagai pelampiasan kekesalan dan kekecewaan. Pelaku bullying kemungkinan besar juga sekedar mengulang apa yang pernah ia lihat dan alami sendiri. Ia menganiaya anak lain karena mungkin ia sendiri di aniaya orang 
tuanya di rumah, atau mungkin pernah ditindas dan di aniaya dengan anak lain yang lebih kuat darinya di masa lalu (Sejiwa, 2008). Artinya tidak menutup kemungkinan bahwa seorang yang tadinya adalah sasaran dari tindak bullying seiring waktu berjalan karena sakit hatinya sehingga berevolusi menjadi pelaku bullying yang suka mengintimidasi orang yang lebih lemah darinya

Maraknya kasus bullying di Indonesia sudah menjadi permasalah utama dalam berbagai bidang terkhusus dunia pendidikan. Tercatat ada sekitar 26 ribu kasus anak dalam kurun waktu 2011 hingga september 2017 yang di laporkan kepada Komisi Perlindungan Anak Indonesia (KPAI). Laporan yang diterima KPAI adalah anak yang berhadapan dengan hukum sebanyak 34\% salah satunya adalah kasus Tamrin City yang melibatkan siswi SMP (dikutip dari www.kpai.go.id). Beberapa di antara mereka ada yang sampai nekad mengakhiri hidupnya karena tidak sanggup lagi menahan beban psikologis yang mereka tanggung sendiri.

Indonesia pernah dihadapi dengan kasus bullying yang di lakukan oleh remaja SMP di Tamrin City Jakarta Pusat. Kejadian ini bermula dari aksi saling mengejek antara pelaku dan korban, dari aksi adu mulut itulah kemudian pelaku kesal dan menjambak rambut korban hingga terjatuh. Siswi yang masih mengenakan seragam putihputih itu tampak terpojok dikelilingi siswi lainnya yang bukannya malah memisahkan tetapi sejumlah siswa yang menonton malah meminta agar korban mencium tangan dua orang yang mem-bullynya. Alhasil dari kejadian itu, sembilan siswa pelaku bullying dikeluarkan dari sekolahnya, tak hanya itu saja Kartu Jakarta Pintar (KJP) yang mereka dapat juga di cabut dengan cara tidak terhormat (dirilis dari www.detik.com).

Di lain tempat, tepatnya di Kecamatan Mumbulsari, Kabupaten Jember, Jawa Timur kasus pemukulan serupa terjadi lagi, seorang siswi SMP memukul temannya sendiri yang diketahui sebagai kakak kelas korban. Aksi pemukulan ini dipicu karena kesalahpahaman dimana pelaku merasa tersinggung karena mendenganr informasi bahwa dirinya digosipi sebagai anak yang nakal, namun setelah di konfirmasikan lagi, korban tidak pernah menggosipi pelaku (dirilis dari www.kompas.com) 
Sebagai penguat penelitian terhadap fenomena bullying di kalangan remaja SMAdi Kota Bandar Lampung, peneliti melakukan wawancara dan observasi di SMA Negeri 7 Kota Bandar Lampung terhadap beberapa guru dan siswa. Hasil temuan menunjukkan bahwa kasus bullying terjadi kepada siswa kelas $\mathrm{X}$ yang memiliki prestasi tinggi di sekolah namun tidak mau memberikan contekan kepada kawan-kawannya sehingga ia menjadi bahan olok-olokan. Kasus lainnya seperti memanggil dengan julukan buruk, mengintimidasi kawan yang bodoh, serta aksi pemukulan dengan intensitas rendah juga kerap di temukan pada beberapa siswa yang bermasalah.

Fenomena bullying dalam kelas sosial tidak bisa dilepaskan dari karakteristik kepribadian seseorang (Howard \& Miriam, 2006).Rigby (2003) menjelaskan Individu yang terlibat dalam tindakan bullying baik sebagai pelaku maupun korban, tidak terlepas dari keperibadian yang mereka miliki. Seseorang yang awalnya hanya ikut-ikutan dan mencontoh dari lingkungan yang terdidik keras tidak menutup kemungkinan nantinya akan membentuk pribadi yang juga keras terhadap orang yang berada di sekitarnya. Kebanyakan orang yang menjadi target intimidasi biasanya memiliki kepribadian yang lemah dan tidak mampu untuk melawan orang yang menindasnya. Sebagai penegasan dalam masalah bullying yang semakin marak terjadi di kalangan remaja ini salah satu nya adalah dengan mengetahui tentang tipe kepribadian yang dimiliki oleh perilaku yang memiliki kecendrungan melakukan tindak bullying yang akan sangat unik dan berbeda dengan yang lainnya.

\section{Metode Penelitian}

Penelitian ini menggunakan pendekatan kuantitatif dengan analisis multiple regression. Populasi pada penelitian ini adalah siswa/siswi SMA Negeri 7 Bandar Lampung yang duduk di kelas X dan XI, berusia 15-17 tahun serta pernah melakukan tindak bullying minimal dalam satu bentuk penindasan.. selanjutnya, peneliti mengambil sampel sebanyak 86 orang dari populasi tersebut secara 
purposive sampling. Pengambilan data dilakukan tanggal 16-28 April 2018.

Skala yang digunakan untuk pengukur kepribadian big five adalah adaptasi dari International Personality Item Pool - Big Five Markers (IPIP-BFM-50) yang dibuat oleh Lewis Goldberg dan telah diterjemahkan oleh Hanif Akhtar dan Syaifuddin Azwar. Skala berjumlah 37 aitem valid dari 50 aitem.

Skala yang digunakan untuk mengujur kecenderungan perilaku bullying adalah skala yang peneliti buat sendiri berdasarkan bentuk-bentuk perilaku bullying merujuk pada teori yang dikemukakan oleh Chakrawati (2015) yaitu fisik, verbal, dan psikis. Skala terdiri dari 35 aitem valid dari 52 aitem.

\section{Hasil dan Pembahasan}

Dari hasil analisis multiple regression diperoleh $R$-Square sebesar 0,275 atau 27,5\% artinya proporsi varians dari kecenderungan perilaku bullying yang dijelaskan oleh variabel independen adalah $27,5 \%$ sedangkan $72,5 \%$ sisanya dipengaruhi oleh variabel lain diluar penelitian ini.

\section{Tabel 1.}

Tabel Anova Kecenderungan Perilaku Bullying

\begin{tabular}{cccccc}
\hline Model & $\begin{array}{c}\text { Sum of } \\
\text { Squares }\end{array}$ & Df & $\begin{array}{c}\text { Mean } \\
\text { Square }\end{array}$ & F & Sig \\
Regression & 434,216 & 5 & & 6,084 & $0,000^{\mathrm{a}}$ \\
Residual & 11530,621 & 80 & 876,843 & & \\
Total & 15914,837 & 85 & 144,133 & & \\
\hline
\end{tabular}

Tabel 1 menunjukan bahwa model memiliki fit yang baik (sig $>0,05)$ yang mengidentifikasi bahwa model regresi sesuai dengan data. Dengan kata lain dapat disimpulkan bahwa hipotesis nihil yang menyatakan tidak ada hubungan yangvsignifikan antara kecenderungan perilaku bullying dengan kepribadian big five ditolak. Artinya ada pengaruh yang signifikan dari kepribadian big five terhadap kecenderungan perilaku bullying.

Tabel 2.

Tabel Koefisien Regresi

$\begin{array}{llll}\text { Model Unstandardized } & \text { Standardized } & \text { Sig. } & \text { Ket }\end{array}$




\begin{tabular}{|c|c|c|c|c|c|}
\hline & \multicolumn{2}{|c|}{ Coefficients } & \multirow[t]{2}{*}{ Coefficients } & & \\
\hline & B & $\begin{array}{l}\text { Std. } \\
\text { Error }\end{array}$ & & & \\
\hline (Constant) & 80,740 & 12,263 & 0,000 & 0,000 & $\begin{array}{c}\text { Tidak } \\
\text { Signifikan }\end{array}$ \\
\hline Extraversion & 0,693 & 0,374 & 0,067 & 0,067 & $\begin{array}{c}\text { Tidak } \\
\text { Signifikan }\end{array}$ \\
\hline Agreebleness & $-0,505$ & 0,352 & 0,155 & 0,155 & $\begin{array}{c}\text { Tidak } \\
\text { Signifikan }\end{array}$ \\
\hline $\begin{array}{r}\text { Emotional } \\
\text { Stability }\end{array}$ & $-0,882$ & 0,286 & 0,003 & 0,003 & Signifikan \\
\hline $\begin{array}{r}\text { Coscientiousn } \\
\text { ess }\end{array}$ & $-0,403$ & 0,259 & 0,124 & 0,124 & $\begin{array}{c}\text { Tidak } \\
\text { Signifikan }\end{array}$ \\
\hline Intellect & 1,159 & 0,421 & 0,007 & 0,007 & Signifikan \\
\hline
\end{tabular}

Berdasarkan pada tabel tersebut dapat diketahui persamaan regresi sebagai berikut :

Kecenderungan perilaku bullying memiliki nilai beta 80,740, extraversion $+0,067$, agreebleness $-0,155$, emotional stability $0,003 *$, conscientiousness $-0,124$ dan intellect $+0,007 *$.

Tanda bintang $(*)$ pada persamaan di atas menandakan bahwa tipe kepribadian emotional stability dan intellect memiliki pengaruh yang signifikan terhadap kecenderungan perilaku bullying.

Penjelasan dari nilai koefisien regresi yang diperoleh pada masing-masing variabel adalah sebagai berikut :

1. Variabel extraversion

Diperoleh nilai koefisien regresi sebesar 0,693 dengan signifikansi sebesar 0,067 (sig. > 0,05), hal ini menunjukkan bahwa variabel secara positif tidak mempengaruhi secara signifikan terhadap kecenderungan perilaku bullying.

2. Variabel agreebleness

Diperoleh nilai koefisien regresi sebesar $-0,505$ dengan signifikansi sebesar 0,155 (sig. > 0,05), hal ini menunjukkan bahwa variabel agreebleness secara negatif tidak mempengaruhi secara signifikan terhadap kecenderungan perilaku bullying.

3. Variabel emotional stability

Diperoleh nilai koefisien regresi sebesar -0,882 dengan signifikansi sebesar 0,003 (sig. < 0,05), hal ini menunjukkan bahwa variabel emotional stability secara negatif mempengaruhi 
secara signifikan terhadap kecenderungan perilaku bullying. Artinya, semakin tinggi variabel emotional stability maka semakin rendah tingkat kecenderungan perilaku bullying.

4. Variabel coscientiousness

Diperoleh nilai koefisien regresi sebesar -0,403 dengan signifikansi sebesar 0,124 (sig. > 0,05), hal ini menunjukkan bahwa variabel coscientiousness secara negatif tidak mempengaruhi secara signifikan terhadap kecenderungan perilaku bullying.

5. Variabel intellect

Diperoleh nilai koefisien regresi sebesar 1,159 dengan signifikansi sebesar 0,007 (sig. < 0,05), hal ini menunjukkan bahwa variabel intellect secara positif mempengaruhi secara signifikan terhadap kecenderungan perilaku bullying. Artinya, semakin tinggi variabel intellectmaka semakin tinggi tingkat kecenderungan perilaku bullying.

\section{Tabel 3.}

Sumbangan Efektif dan Sumbangan Relatif

\begin{tabular}{rccllc}
\hline Variabel & $\begin{array}{c}\text { Koefisien } \\
\text { Regresi } \\
\text { (Beta) }\end{array}$ & $\begin{array}{c}\text { Koefisien } \\
\text { korelasi }\end{array}$ & $\begin{array}{c}\text { Sumbangan } \\
\text { Efektif } \mathbf{( \% )}\end{array}$ & $\begin{array}{c}\text { Sumbangan } \\
\text { Relatif }(\boldsymbol{\%})\end{array}$ & $\begin{array}{c}\text { Sig. F } \\
\text { Change }\end{array}$ \\
$\begin{array}{r}\text { Extraversion } \\
\text { Agreebleness }\end{array}$ & $-0,189$ & 0,189 & $3,1 \%$ & $12,15 \%$ & 0,103 \\
Emotional & $-0,302$ & $-0,163$ & $3,3 \%$ & $7,4 \%$ & 0,093 \\
$\begin{array}{r}\text { Stability } \\
\text { Coscientiousn }\end{array}$ & $-0,302$ & $12,6 \%$ & $41,2 \%$ & 0,001 \\
ess & & $-0,169$ & $1,7 \%$ & $10,6 \%$ & 0,194 \\
Intellect & 0,293 & 0,293 & $6,9 \%$ & $28,65 \%$ & 0,007 \\
\hline
\end{tabular}

Berdasarkan tabel 3 di atas menunjukkan bahwa Variabel emotional stability memberikan sumbangan efektif sebesar 12,6\% dan sumbangan relatif sebesar $41,2 \%$ dalam varians kecenderungan perilaku bullying. Sumbangan tersebut memiliki hubungan yang signifikan secara statistik dengan $\mathrm{F}=0,001$.

Variabel intellect memberikan sumbangan efektif sebesar $6,9 \%$ dan sumbangan relatif sebesar $28,65 \%$ dalam varians 
kecenderungan perilaku bullying. Sumbangan tersebut memiliki hubungan yang signifikan secara statistik dengan $F=0,007$.

Hasil penelitian menunjukkan bahwa terdapat dua dimensi kepribadian yang mempengaruhi secara signifikan terhadap kecenderungan perilaku bullying. Pertama, dimensi emotional stability yangsecara negatif mempengaruhi secara signifikan terhadap kecenderungan perilaku bullying, hal ini menunjukkan bahwa seseorang yang semakin tinggi variabel emotional stability pada tipe kepribadian big five maka semakin rendah tingkat kecenderungan perilaku bullying. Kedua, dimensi kepribadian intellect yang secara positif mempengatuhi secara signifikan terhadap kecenderungan perilaku bullying, hal ini menunjukkanbahwa seseorang yang semakin tinggi variabel intellect pada tipe kepribadian big five maka semakin tinggi tingkat kecenderungan perilaku bullying.

Menurut Feist, Gregory dan Tomi (2017) menerangkan bahwa kepribadian mencakup sistem fisik dan psikologis meliputi perilaku yang terlihat dan pikiran yang tidak terlihat, serta tidak hanya merupakan sesuatu, tetapi melakukan sesuatu. Berkaitan dengan itu dapat diartikan bahwakepribadian seorang anak dapat menentukan respons yang dia miliki untukmenemukan reaksi mana yang merupakan penentu utama status bullying pada diri anak baik sebagai penindas maupun yang ditindas (Bollmer dkk, 2005).

Pada dimensi kepribadian extraversion, hasil yang telah diperoleh dalam penelitian ini adalah hipotesis ditolak. Hal ini menunjukkan bahwa extraversion tidak memiliki pengaruh yang signifikan terhadap kecenderungan perilaku bullying. Penelitian lain yang dilakukan oleh Larasati (2016) menyatakan bahwa tidak ada hubungan atntara tipe kepribadian big five dengan perilaku cyberbullying. Beberapa jurnal menyatakan bahwa tipe kepribadian extraversion memiliki hubungan yang positif dengan perilaku bullying yang berarti ketika seseorang memiliki nilai kepribadian extraversion yang tinggi maka orang tersebut juga cenderung tinggi melakukan tindak bullying. Ciri-ciri seseorang yang tinggi pada tipe kepribadian extraversion yaitu mudah bersosialisasi, banyak berbicara, tegas, energik, aktif, giat, menyenangkan, mudah bergaul dan penuh kasih sayang (Sari, 2010). 
Menurut McCrae dan Costa (dalam Feist, Gregory \& Tomi, 2017) individu dengan tipe kepribadian extraversion cendrung memiliki kecakapan sosial yang baik, hal ini juga dapat diartikan sebagai 'dapat diterima secara sosial', kompetensi sosial yang baik ini dapat membantu dalam memilih strategi konflik resolusi yang lebih positif serta berperilaku sesuai dengan etika. Hasil dari penelitian yang dilakukan oleh Larasari (2016) menyatakan remaja yang terlibat dalam bullying, memiliki kemampuan menyelesaikan masalah yang buruk yang akhirinya mendorong mereka menjadi pelaku ataupun korban, Dari penelitian tersebut telah mendukung penelitian ini bahwa tipe kepribadian extraversion tidak mempengaruhi seseorang dalam berperilaku bullying.

Hal tersebut juga terjadi pada tipe kepribadian agreebleness. Ciri kepribadian pada tipe ini adalah berhati lembut, ramah, toleran, bersahabat dan dermawan (Feist, Gregory \& Tomi, 2017). Penelitian yang dilakukan oleh Diepenhorst (2014) menyatakan bahwa pada tipe kepribadian agreebleness menunjukkan skor yang rendah pada kelompok orang yang melakukan penindasan artinya penelitian ini berkorelasi secara negatif. Namun di sisi lain, pelaku bullying di sekolah dapat menyamar sebagai teman korban, bersikap baik dan seolah-olah memberikan perhatian, mereka melemparkan komentarkomentar yang tampaknya biasa, misal tentang berat badan yang sebenarnya hal itu merupakan strategi agar seolah-olah tampak humoris namun sebenarnya mereka sedang mempertimbangkan serangan (Wharton, 2009). Kejadian tersebut dapat dijadikan penguat pada penelitian ini bahwa tidak ada hubungan yang signifikan antara kepribadian big five dengan kecenderungan perilaku bullying pada remaja di sekolah, dengan kata lain bahwa hipotesis ditolak.

Seseorang yang tinggi pada kepribadian emotional stability akan memiliki ciri-ciri tingkat rektivitas dan stabilitas emosi, resistensi emosional dan toleransi terhadap rasa frustasi (Strus dkk, 2017). Penelitian ini memberikan hasil bahwa ada hubungan yang signifikan secara negatif antara tipe kepribadian big five dengan kecendrungan perilaku bullying artinya semakin rendah seseorang pada tipe kepribadian ini maka semakin tinggi perilaku bullying. Penelitian ini didukung juga oleh Sejiwa (2008) yang menjelaskan 
bahwa seorang pelaku bullying kurang memiliki kecakapan dalam mengontrol emosinya dan cenderung tempramental, mereka melakukan bullying terhadap orang lain sebagai bentuk pelampiasan kekesalan dan kekecewaannya.

Pada tipe kepribadian conscientiousnessseseorangakan memiliki ciri-ciri seperti berhati-hati, dapat diandalkan, teratur, dan bertanggung jawab (Fredman, 2006). Dalam penelitian ini tipe kepribadian conscientiousnesstidak memiliki hubungan yang signifikan dengan kecenderungan perilaku bullying, yang artinya hipotesis ditolak. Hal ini serupa dengan penelitian yang dilakukan oleh Argayunia (2017) yang dari lima tipe kepribadian hanya ada tiga yang berkorelasi signifikan yaitu eontional stability, agreebleness, dan intellect.

McCrae dan Costa (dalam dalam Feist, Gregory \& Tomi, 2017) memaparkan seseorang yang tinggi pada tipe kepribadian intellect akan memiliki ciri-ciri yaitu kreatif, imajinatif, inovatif, penasaran, serta bebas. Hal inilah yang selalu dijadikan senjata bagi pelaku bullying untuk menyusun berbagai strategi andal untuk melukai korbannya (Coroloso, 2007). Dalam penelitian ini tipe kepribadian intellect memiliki hubungan yang signifikan secara positif dengan kecenderungan perilaku bullying artinya semakin tinggi seseorang pada tipe kepribadian intellect maka akan semakin tinggi perilaku bullying yang terjadi. Penindas selalu punya cara untuk melukai korbannya (Sejiwa, 2008).

Kepribadian merupakan hal yang memiliki korelasi dengan terbentuknya perilaku bullying di sekolah (Rahmawati, 2014). Allport (dalam Fredman, 2006) Menyebutkan bahwa komponen dasar trait merupakan bagian inti yang koheren dari kepribadian, trait sendiri merupakan potensi seseorang untuk merespon sesuatu yang dapat mengarahkan kepada bentuk-bentuk perilaku manusia secara konsisten. Dengan demikian, penting untuk mengetahui tipe kepribadian siswa yang berpotensi melakukan tindak bullying agar segera mendapatkan penanganan. 


\section{Simpulan dan Saran}

Hasil penelitian ini menunjukkan bahwa terdapat hubungan antara tipe kepribadian dan kecenderungan perilaku bullying. Adapun saran untuk penelitian selanjutnya yang tertarik untuk meneliti kembali perihal perilaku bullying diharapkan dapat mempertimbangkan kembali variabel-variabel lain yang mempengaruhi, seperti pola asuh orang tua, locus of conrol, dan religiusitas.

\section{Referensi}

Akhtar, H., \& Azwar, S. (2018). Buku Petunjuk Penggunaan IPIPBFM-50 Kepribadian Big Five. Yogyakarta : Fakultas Psikologi Universitas Gajah Mada.

Argayunia, D. (2017). Hubungan Keperibadian Big Five dengan Perilaku Bullying pada Anggota Kepolisian Resor Magelang Kota.Skripsi. (Tidak Diterbitkan). Yogyakarta : Fakultas Ilmu Sosial dan Humaniora.

Azwar, S. (2000). Metode Penelitian.Yogyakarta : Pustaka Pelajar. . (2012). Penyusunan Skala Psikologi. Yogyakarta : Pustaka Pelajar.

. (2014). Reliabilitas dan Validitas. Yogyakarta : Pustaka Pelajar.

Bollmer JM., Monica JH., \& Richard M. (2005). Reactions to Bullying and Peer Victimization: Narratives, physiological Arousal, and Personality. Journal of Research in Personality. USA: Department of Psychology, University of Kentucky , 40, 803-828.

Chakrawati, F. (2015). Bullying, Siapa Takut?. Solo : PT. Tiga Serangkai Pustaka Mandiri.

Coloroso, B. (2007). Stop Bullying: memutus Rantai Kekerasan Anak dari Prasekolah Hingga SMU. Jakarta : PT. Serambi Ilmu Semesta.

Feist J., Gregory JF., \& Tomi-an R. (2017). Teori Keperibadian. Jakarta : Salemba Humanika. 
Friedman., Howard S., \& Miriam WS. (2006). Keperibadian: Teori Klasik dan Riset Modern. Jakarta : PT. Gelora Aksara Pratama.

Larasati, A., \& Maya F. (2016). Kecendrungan Perilaku Cyberbullying Ditinjau dari Trait dalam Pendekatan Big-Five Personality pada Siswa Sekloah Menengah Atas Negeri Kota Yogyakarta. Jurnal Psikologi Integratif 4 (2). 161-182.

Okfianto, HT. (2017). Profil Sekolah SMA Negeri 7 Bandar Lampung. http://sman7bandarlampung.sch.id. Diakses pada tanggal 6 Juni 2018.

Rahmawati, SW. (2014). Hubungan antara Tait Kepribadian Lima Besar dengan Pelaku Bullying pada Siswa SMK. Jurnal Psiko Utama 4 (2). 1-10.

Regional. (2018). Siswa SMP Pukul dan Tendang Temannyadi Jember karena Salah Paham.https://regional.kompas.com. Diakses pada tanggal 22 Juni 2018.

Rigby, K. (2002). New Perspectives on Bullying. London : Jessica Kingsley.

Santrock, JW. (2003). Adolescence: Perkembangan Remaja. Jakarta : Penerbit Erlangga.

Sari, DA. (2010). Uji Validitas Alat Ukur Big Five Personality (adaptasi dari IPIP) pada Mahasiswa Universitas Islam Negeri Syarif Hidayatullah Jakarta. Skripsi. (Tidak Diterbitkan) Jakarta : Fakutas Psikologi Universitas Islam Negeri Syarif Hidayatullah.

Setyawan, D. (2017). Terima Aduan 26 Ribu kasus Bully selama 2011-2017. http://www.kpai.go.id. Diakses pada tanggal 30 Januari 2018.

Sejiwa, (2008). Bullying: Mengatasi Kekerasan di Sekolah dan Lingkungan Sekitar Anak. Jakarta : PT. Grasindo.

Strus, W., Cieciuch, J \& Rowinski, T. (2017) The Polish adaptation of the IPIP-BFM-50-50 questionnaire for measuring five personality traits in the lexical approach. Roczniki Psychologiczne/Annals of Psychology 17(2). 347-366.

Wharton, S. (2005). How to Stop that Bully. Yogyakarta: Kanisius. 